\title{
An Accuracy Analysis Comparison of Supervised Classification Methods for Mapping Land Cover Using Sentinel 2 Images in the Al-Hawizeh Marsh Area, Southern Iraq
}

\begin{abstract}
Land cover mapping of marshland areas from satellite images data is not a simple process, due to the similarity of the spectral characteristics of the land cover. This leads to challenges being encountered with some land covers classes, especially in wetlands classes. In this study, satellite images from the Sentinel 2B by ESA (European Space Agency) were used to classify the land cover of Al-Hawizeh marsh/Iraq-Iran border. Three classification methods were used aimed at comparing their accuracy, using multispectral satellite images with a spatial resolution of $10 \mathrm{~m}$. The classification process was performed using three different algorithms, namely: Maximum Likelihood Classification (MLC), Artificial Neural Networks (ANN), and Support Vector Machine (SVM). The classification algorithms were carried out using ENVI 5.1 software to detect six land cover classes: deep water marsh, shallow water marsh, marsh vegetation (aquatic vegetation), urban area (built-up area), agriculture area, and barren soil. The results showed that the MLC method applied to Sentinel 2B images provides a higher overall accuracy and the kappa coefficient compared to the ANN and SVM methods. Overall accuracy values for MLC, ANN, and SVM methods were $85.32 \%, 70.64 \%$, and $77.01 \%$ respectively.
\end{abstract}

Keywords: land cover mapping, Sentinel 2, supervised classification, maximum likelihood, Support Vector Machine (SVM), confusion matrix

Received: 15 July 2020; accepted: 8 September 2020

(C) 2021 Authors. This is an open access publication, which can be used, distributed and reproduced in any medium according to the Creative Commons CC-BY 4.0 License.

University of Technology, Civil Engineering Department, Baghdad 10066, Iraq, email: 40164@uotechnology.edu.iq, ORCID ID: https://orcid.org/0000-0002-8128-6658

2 Ministry of Science and Technology, Directorate of Space and Communication, Baghdad 10070, Iraq, email: nadia_naa@yahoo.com, ORCID ID: https://orcid.org/0000-0003-1978-7432 


\section{Introduction}

Marshlands represent one of the richest areas of biodiversity in Iraq's ecosystems [1]. The Mesopotamian Marshes (Ahwar of Southern Iraq) is unique in that it is one of the world's largest inland delta systems in an extremely hot and arid environment [2], it plays an important role in global ecosystems by supporting rare wildlife and rich biodiversity, especially of migratory birds [3]. In 2016, Al Ahwar was listed as a UNESCO World Heritage site, recognizing its significance for biodiversity and preserving Mesopotamian heritage [4]. Therefore, the restoration and protection of the marshlands are of primary importance for socioeconomic development in Iraq. Historically, the marshlands included a chain of almost interconnected permanent and seasonal marshes, shallow and deep lake units that merged into larger wetland complexes during high floods; mudflats and desert regularly inundated in periods of elevated water levels; and a great variety of habitats and ecological features [5]. The Al-Hawizeh marsh is part of the Mesopotamian Marshes that included in the Ramsar list of wetlands of international importance as they regularly harbor considerable numbers of threatened, endemic, and restricted-ranged bird and mammal species and they also provide a home and livelihoods for many of the indigenous people living there.

During the Iran-Iraq war (1980-1988), Al-Hawizeh marsh Drainage began with the construction of oil fields, the area witnessed many battles, where both of the conflicting sides drained and flooded the marshes for tactical military reasons such as aiding advancing and retreating troops. In the 1990s, Al-Hawizeh Marsh suffered again from drainage by water diversion, the construction of embankments and sluice gates along the Tigris and its tributaries; and by dam construction on the Al Karkheh River in Iran. After the fall of the Iraqi regime in 2003, the marshes of Iraq were no longer a banned area. Local unauthorized citizens started to release water back to the former wetlands from artificial canals and reservoirs randomly with no direction or plan [6]. Over recent decades, the land cover in Al-Hawizeh marshes have changed dramatically due to water release and the filling of the lowlands, so that it is very important to produce high-resolution land cover maps for management and sustainable development in this important area.

Remotely sensed imagery (e.g., aerial photographs, digital imagery, and satellite imagery) provide an effective tool to study the land cover. Aerial photographs have been used for decades to identify wetlands and other natural resources for site-specific assessments and for producing thematic maps for wetland inventories and land cover surveys. Aerial photographs have been converted to digital images for onscreen interpretation using geographic information system (GIS) technology. Satellite imagery and other remotely sensed data are more recent sources of wetland type and distribution data. Given the advent of unmanned aerial systems (UASs) and high-resolution multispectral imagery, environmental specialists have new tools and information for optimizing management decisions and enabling precision 
environmental solutions. Additionally, the CORINE Land Cover system provides the only consistent classification system of long-term land cover data in Europe, the most commonly applied method to map CORINE land cover change is by visual interpretation of optical/near-infrared satellite imagery. Thematic maps prepared by interpreting remotely sensed imagery (e.g., aerial photos, satellite imagery, or other spectral data) have inherent limitations related to many factors, including the nature of the resources being mapped (e.g., their ease or difficulty of recognition), map scale (e.g., balancing minimum mapping units against map legibility), quality and scale of source imagery, environmental conditions present when imagery/sensor data were captured (e.g., leaf-on, leaf-off, wet season, or dry season), the film emulsion (for photos), the spectral bands analyzed (for satellite imagery). Satellite imagery provides a wide range of monitoring capabilities in a rapid manner, especially for areas unavailable for field surveys due to terrain, dense vegetation, or another obstacle [7]. High-resolution land cover and land use classifications have applications in many fields of study such as land use and cover change, carbon storage measurements, and environmental impact assessments [8-11]. Remote sensing images are attractive data sources to derive land cover information using image classifications. Image classifications can be grouped under two main categories, namely parametric and nonparametric methods. The parametric methods assume that the observation matrix comes from a known probability distribution and make inferences about the parameters of the distribution, while nonparametric methods do not require the variables in the image matrix to belong to any particular distribution $[12,13]$. Various parametric classifiers, such as the maximum likelihood classifier (MLC), and non-parametric classifiers, such as the Artificial Neural Networks (ANN), were successfully employed to classify multispectral images. Recently, support vector machines (SVM) have also been proposed as an alternative classification method for both multi and hyperspectral data.

Many previous studies have been conducted to evaluate the accuracy of the classification methods, which is considered as a fundamental component of any mapping project that counts on remote sensing; thematic accuracy assessment depends on the measurement of qualities of general and categorical data [14]. Talukdar et al. [15] examined six machine-learning algorithms to assess the accuracy of these methods using the kappa coefficient, receiver operational curve, index-based validation, and root mean square error. Nguyen et al. [16] evaluate Sentinel 2 data for land cover classification, and compare parametric classifiers with three non-parametric classifiers using overall and class-level accuracies, and a few studies on the use of SVM for land cover classification and its accuracy assessment have been reported in recent years.

This study aims to classify the land cover of the Al-Hawizeh marsh using three classification methods (MLC, ANN, and SVM) to compare the accuracy of classification methods using satellite images from Sentinel 2B. This study could be helpful for wetland environmental policy planning and decision-making for the sustainable development of the marshland area. 


\section{Materials and Methods}

\subsection{Site Description}

The Al-Hawizeh Marsh lies to the east of the Tigris River, straddling the Iran-Iraq border. The Iranian section of the marsh is known as Houwr Al-Azim, where it is fed primarily by the Al Karkheh River [6]. The marsh areas straddle the international border between Iraq and Iran, with approximately $80 \%$ of the marsh in Iraq and $20 \%$ in Iran [17]. Iran constructed an embankment with several spillways that divide the eastern and western portions of the marsh near the border. The area of the marsh is approximately $3000 \mathrm{~km}^{2}$ [3]. The marsh is permanently in its northern and central parts, but it becomes increasingly seasonal towards the southern sections. Typically, dense aquatic vegetation alternating with open extensions of water characterizes the permanent parts of the marsh. Land use within and adjacent to Al-Hawizeh Marsh areas includes villages and towns, agricultural areas, and oil fields. The southeastern part is referred to as the "Majnoon marsh", which receives water from the Al-Hawizeh marsh and its size decreases substantially during dry years. The Majnoon marsh is characterized by large, seasonal areas of open water, some areas of dense reeds, and scrublands that flood annually. A supergiant oil field is located under the Majnoon marsh, and much of this area has been dried to allow for oil extraction [18]. The annual allocation of freshwater to Al-Hawizeh Marsh is $2.6 \mathrm{BCM}$ from Iraq and the potential inflow from Iran is about 1.19 BCM [19]. The total studied area is $5258.72 \mathrm{~km}^{2}$, which lies in the arid zone [20] between longitudes $47^{\circ} 24^{\prime}-48^{\circ} 00^{\prime} \mathrm{E}$, and latitudes $30^{\circ} 50^{\prime}-32^{\circ} 00^{\prime} \mathrm{N}$ as shown in Figure 1.

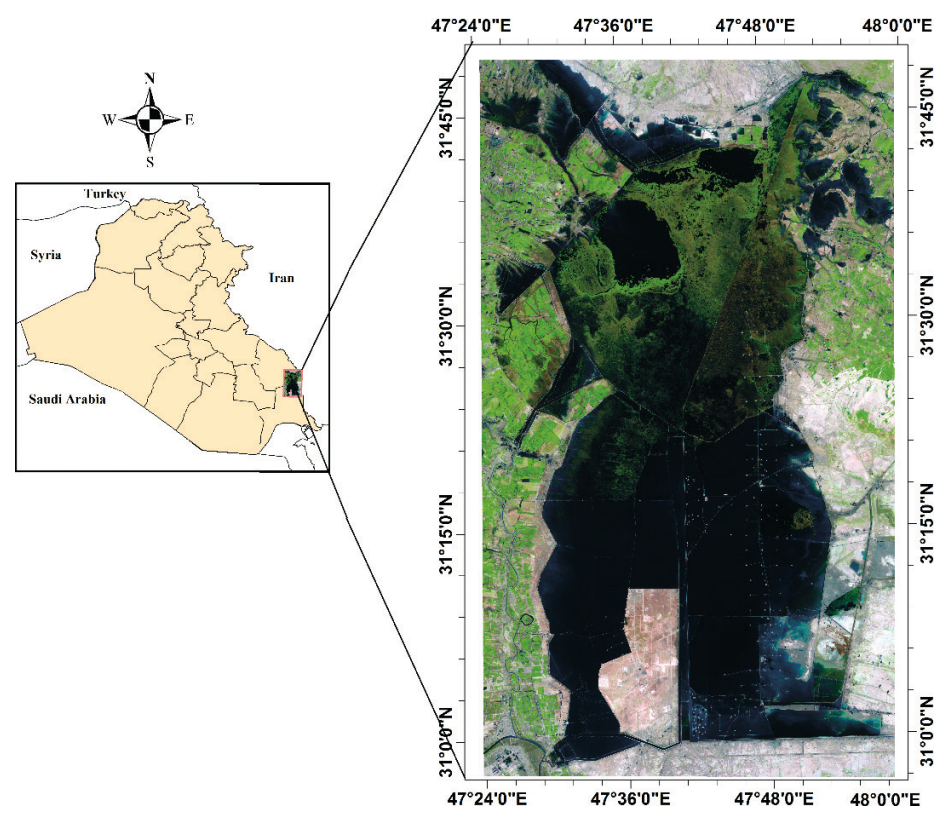

Fig. 1. The study area location based on the Sentinel 2B Image on March 2020 


\subsection{Dataset}

Sentinel 2B multispectral images cover 13 spectrum bands (443-2190 nm), with a swath width equals to $290 \mathrm{~km}$ and a spatial resolution of 10 (four visible and near-infrared bands), 20 (six red edge and shortwave infrared bands), and $60 \mathrm{~m}$ (three atmospheric correction bands) [21]. Two images were selected and download from the ESA-Hub website [22] with zero cloud coverage and the capture date was on 6 March 2020. The two images were combined with RGB set, combined in a single scene by mosaicking process, and then the study area was extracted.

The marsh water depth data were collected from the Ministry of Water Resources/ Center for Restoration of Iraqi Marshlands [23]. The data were collected using an echo sounder (Garmin 178C) combined with GPS to measure the marsh bed data as $\mathrm{X}, \mathrm{Y}, \mathrm{Z}$ format, and then the data is presented in a raster form as shown in Figure 2; where the deeper marsh water approximately ranged from 6-9 $\mathrm{m}$ in the northern and central parts. The data about the southeastern part (the Majnoon marsh) are not available, but it is considered as shallow water, where a supergiant oil field is located there and much of this area has been drained to allow for oil extraction.

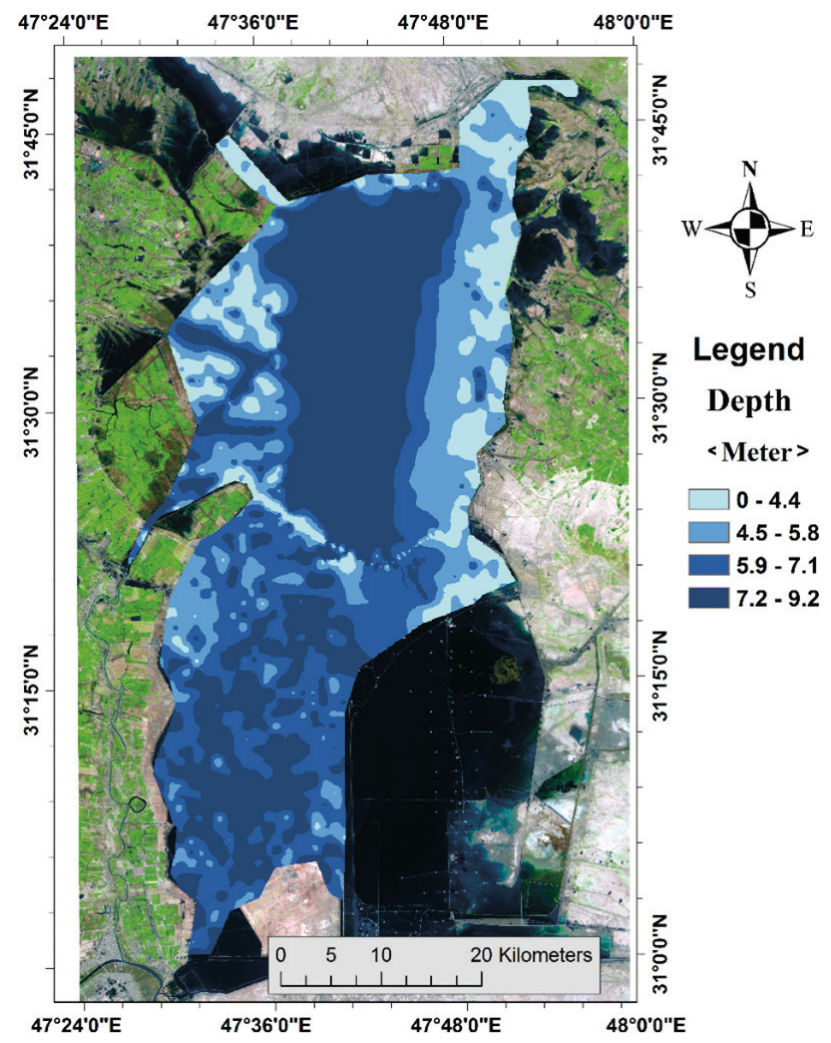

Fig. 2. The marsh depth data 


\subsection{Image Classification}

The principle form of deriving land cover information from remotely sensed images is classification. In the context of remote sensing, classification refers to the process of translating observations into land cover categories with clearly defined bio geophysical functions [24]. These maps are then used in a growing number of environmental applications, from resource management to global change studies. In this study, the classification process was performed using three different algorithms: MLC, ANN, and SVM utilizing the ENVI (version 5.1) remote sensing image processing software. The image classification software uses the spectral signatures of the pixels in the training areas to identify classes in the image [25]. The MLC, ANN, and SVM classification algorithms are derived from statistical theories and commonly used in land cover classification studies [26]. A Region of Interest (ROI) Tool was used to define some sample areas to train the classifier algorithms such as deep water marsh, shallow water marsh, marsh vegetation (aquatic vegetation), urban area, agriculture area, and barren soil. More than 25 samples were taken for each class, with the total number of samples is 172 . The processing procedure for the supervised classifications based on MLC, ANN, and SVM are schematically shown in Figure 3.

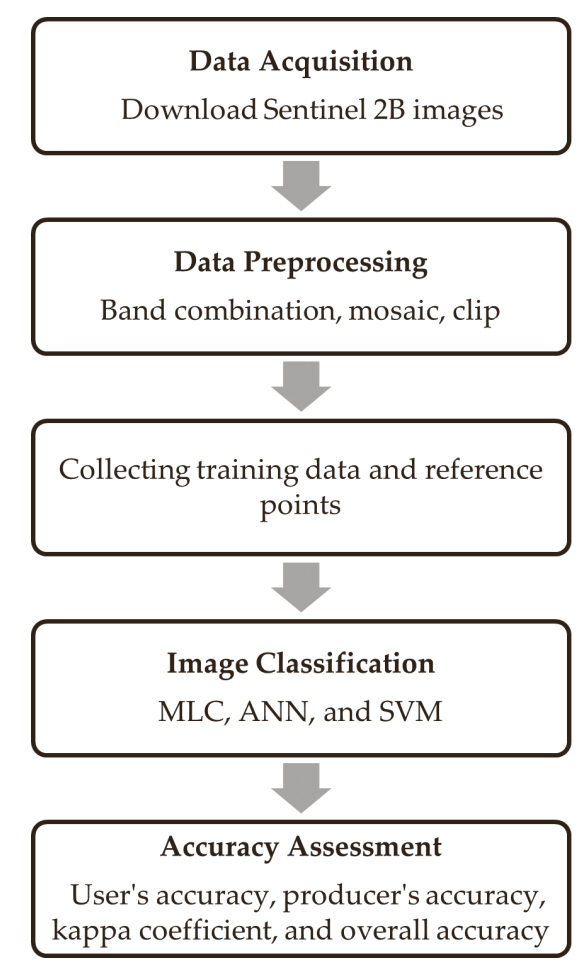

Fig. 3. The methodology steps to perform the classification 


\section{Supervised Maximum Likelihood Classification}

MLC is one of the most common supervised classification methods used in remote sensing classification applications. This method considers the variance-covariance within the class distributions and assumes the data as normally distributed. MLC algorithm needs sufficient representative spectral training sample data for each class, for accurate estimation of the mean vector and covariance matrix. MLC is a parametric classifier based on the probability that a pixel belongs to a particular class, it takes the variability of classes into account by using the covariance matrix. Better results could be obtained with MLC compared to other known parametric classifies if the data set is normally distributed [27]. MLC is based on the Bayesian probability formula [28]:

$$
P(x, w)=P(w \| x) P(x)=P(x \| w) P(w)
$$

where $x$ and $w$ are events, $P(x, w)$ is the coexistence probability of events, $P(x)$ and $P(w)$ are the prior probabilities of events, and $P(w \| x)$ is the conditional probability of event $x$ given event $w$.

\section{Support Vector Machines}

SVM is one of the most effective classification methods. Training sites are selected to create hyperplanes to separate datasets into a predefined number of classes represented by training areas $[29,30]$. Their largest advantage over other classifiers lies in their ability to generalize well, even with limited training samples [31]. Other advantages include that there is no need for prior information about the underlying data distribution and a few training data only are required, making SVM suitable for variable datasets with a relatively low computational cost. However, a major limitation of standard SVM classifiers in image classification is that they produce a crisp output [32]. By mapping SVM input vectors non-linearly into a high-dimension feature space, a decision surface (hyperplane) is set up to differentiate between arbitrary data distributions [33]. The kernel function gives the weights of adjacent data points in assessing target classes. The classification was made using the Radial Basis Function (RBF) kernel type [34] which is a popular kernel method used in SVM models. The RBF kernel formula is [28]:

$$
K(u, v)=\exp ^{-\gamma|u-v|^{2}}
$$

where $\gamma$ is the gamma.

\section{Artificial Neural Networks Classification}

Neural networks are an efficient method in data categorizing into groups or features. Neural network classifications, applied for feature categorization, are quite similar to a fault-diagnosis networks, the exception is that they only permit one output response for any given input pattern, rather than allowing multiple 
faults to occur in a specific set of operating conditions [35]. The categorized selection of the classification network is based on detecting the output response that has the highest output value. A neural network classification becomes highly powerful when applied in a hybrid system with many predictive neural network types [36].

The neural net technique utilizes standard backpropagation for supervised learning. The hidden layers number is used for selection between hyperbolic or logistic activation function. Error backpropagation through the network and weight adjustment is done by a recursive method. Neural net classification could be utilized to implement both linear and non-linear classification [37].

\subsection{Accuracy Assessment}

The accuracy of spatial data as defined by the USGS [38] as "The closeness of the results of observations, computations, or estimates to the true values or the values accepted as being true". In this study, the accuracy assessment was assessed to evaluate the classification results of the MLC, SVM, and ANN classification methods. For classifier training and accuracy assessment of land cover, multiple sets of sample data are required. A per-pixel classification of land cover requires two sample datasets (one for training and one for accuracy assessment) with the number of sample sites being at least ten times the number of image bands used [39], with each sample incorporating as many pixels as possible. All sample sites were located in the middle of homogenous segments of known land cover classes to avoid mixed pixels. Kappa coefficient, overall accuracy, and confusion matrices were selected as accurate measures. Omission and commission error matrix within the confusion matrix are also considered.

The kappa statistic is a measure of the similarity between signature samples and control samples [40], it is a robust process to compare the differences between diverse error matrices [41]. The kappa analysis is a discrete multivariate technique used in accuracy assessment for statistically determining if one error matrix is significantly different than another [42]. Kappa analysis for comparing error matrices assumes a multinomial sampling model. Only simple random sampling completely satisfies this assumption. Rosenfield and Fitzpatrick-Lins [43] recommended the kappa coefficient as a standard. Table 1 shows the accuracy rank for each kappa coefficient. The kappa coefficient equation is:

$$
K=\frac{N \sum_{i=1}^{r} X_{i i}-\sum_{i=1}^{r} X_{i+} X_{+i}}{N^{2}+\sum_{i=1}^{r} X_{i+} X_{+i}}
$$

where $r$ is the number of rows and columns, $N$ is the total number, $X_{i i}$ is the observation in row $i$, and column $i, X_{i+}$ is the marginal total of row $i$, and $X_{+i}$ represents the marginal total of column $i$. 
Table 1. Classification accuracy based on kappa value

\begin{tabular}{|c|c|}
\hline Kappa coefficient & Accuracy level \\
\hline $0.41-0.60$ & moderate \\
\hline $0.61-0.80$ & high \\
\hline$\geq 0.80$ & very high \\
\hline
\end{tabular}

Source: [44]

The most commonly used accuracy assessment is the confusion matrix [45]. In the confusion matrix, the values for the land cover of the reference data is listed in the columns, and for the classified data in the rows. The overall accuracy is a basic accuracy measure, which is calculated by the equation [46]:

$$
\text { Overall accuracy }=\frac{\text { Number of correct classes }}{\text { Total number of classes }}
$$

\section{Results and Discussion}

\subsection{Classification Results}

After obtaining the signature and reference samples, a classification was performed. The three classification algorithms: MLC, SVM, and ANN were performed using the ENVI remote sensing image processing software. Six land cover classes were distinguished (deep water marsh, shallow water marsh, marsh vegetation, urban area, agriculture area, and barren soil) as shown in Figures 4-6, then the area and percentage for each class were calculated as shown in Table 2. The general classification was chosen because this study focuses on the accuracy of classification methods in general. Additionally, more specific classification needs more specific field data that is costly and hard because the study area is located on the national border and a part of it is in Iran.

The SVM classification method gives the larger area percentage for deep-water marsh class compared with MLC and ANN classification methods; while the ANN classification method gives the larger area percentage for the shallow water marsh compared with SVM and MLC methods. Therefore, the SVM and ANN classification methods were more sensitive to the water body class.

The results of MLC and SVM classification methods were more distinct for marsh vegetation (aquatic vegetation) compared with the ANN classification method; while the results of SVM and ANN classification methods give a lower area percentage compared to MLC method, this reflects that MLC method is more sensitive for the urban class. 
Table 2. Area and percentage for each class

\begin{tabular}{||l|c|c|c|c|c|c||}
\hline \multirow{2}{*}{ Class } & \multicolumn{2}{c|}{ MLC } & \multicolumn{2}{c|}{ SVM } & \multicolumn{2}{c||}{ ANN } \\
\cline { 2 - 7 } & $\begin{array}{c}\text { area } \\
{\left[\mathrm{km}^{2}\right]}\end{array}$ & $\begin{array}{c}\text { percentage } \\
{[\%]}\end{array}$ & $\begin{array}{c}\text { area } \\
{\left[\mathrm{km}^{2}\right]}\end{array}$ & $\begin{array}{c}\text { percentage } \\
{[\%]}\end{array}$ & $\begin{array}{c}\text { area } \\
{\left[\mathrm{km}^{2}\right]}\end{array}$ & $\begin{array}{c}\text { percentage } \\
{[\%]}\end{array}$ \\
\hline \hline Deep water marsh & 432.59 & 8.23 & 1415.47 & 26.93 & 815.59 & 15.5 \\
\hline Shallow water marsh & 429.72 & 8.17 & 689.42 & 13.11 & 1497.45 & 28.48 \\
\hline Marsh vegetation & 843.14 & 16.03 & 723.48 & 13.76 & 320.49 & 6.09 \\
\hline Urban area & 460.47 & 8.76 & 1.51 & 0.03 & 2.66 & 0.05 \\
\hline Agriculture area & 851.86 & 16.2 & 311.91 & 5.93 & 219.69 & 4.19 \\
\hline Barren soil & 2240.94 & 42.61 & 2116.93 & 40.24 & 2402.84 & 45.69 \\
\hline Total & 5258.72 & 100 & 5258.72 & 100 & 5258.72 & 100 \\
\hline
\end{tabular}

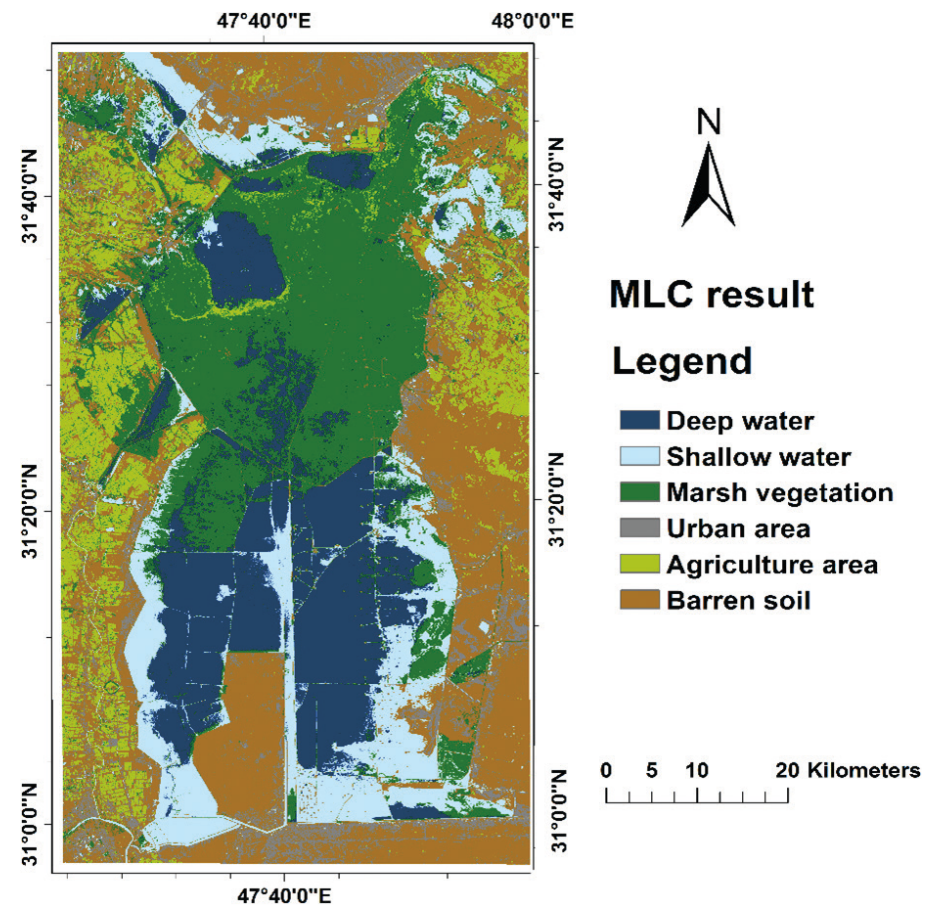

Fig. 4. Classification results for the MLC method 


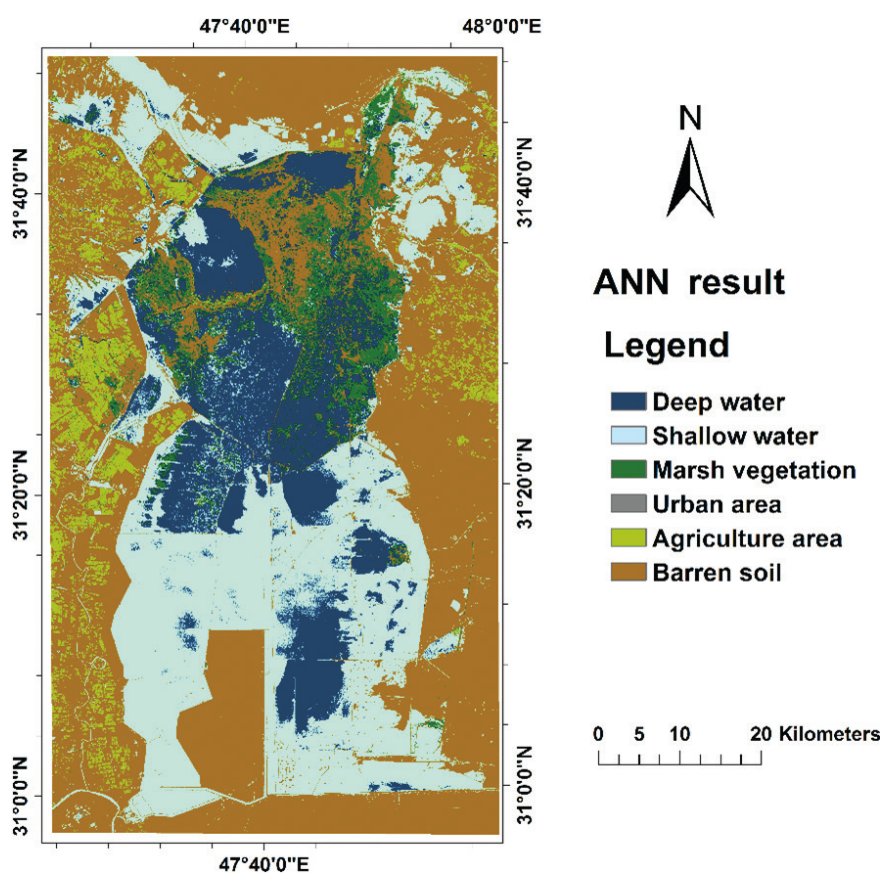

Fig. 5. Classification results for the ANN method

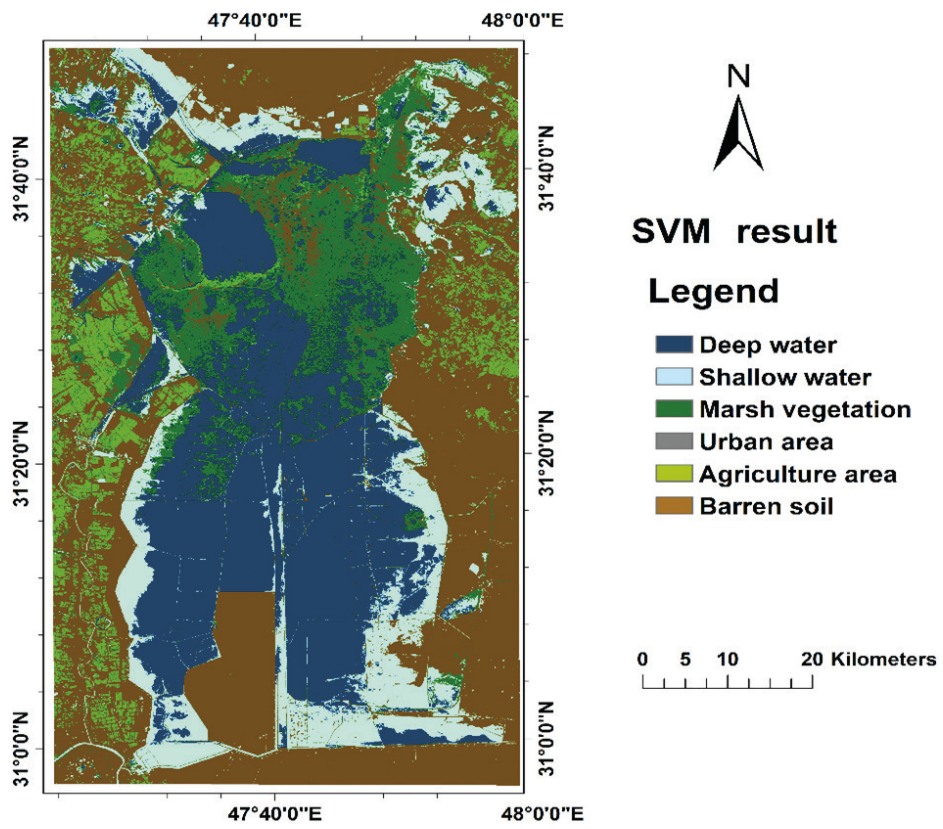

Fig. 6. Classification results for the SVM method 
The results of the MLC classification method give a higher area percentage in agriculture class compared to SVM and ANN classification methods; while the three classification methods give a similar area percentage in barren soil class.

\subsection{Accuracy Evaluation}

The first step to assess accuracy is preparing the reference data, about 60 data points were defined from a total of 360 points created. These points were selected over different locations representing different land cover classes. For the validation of the acquired results, a comparison of the classified images was made against the reference samples data fields using a cross-tabulation matrix. In training fields selection, separability problems between the aquatic vegetation and the agricultural land cover classes were identified, which is showed in the producer's accuracy percentage with mean values lower than $70 \%$. Jointly, the following were acquired: kappa index, shows the similarity degree between a set of control fields and the classified image; the overall accuracy, shows the percentage of pixels classified properly; a percentage of producer's accuracy, sets the percentage of a kind of a given land use correctly classified in the image; and the percentage of user's accuracy, provides the percentage of a land cover class in an image that matches with the corresponding class in the land.

Table 3 shows the results from the process of classified images validation using the cross-tabulation matrix and the obtained parameters: overall accuracy, kappa coefficient, producer's accuracy, and user's accuracy.

The overall accuracy of the MLC classification method was $85.32 \%$ with a kappa value of 0.8236 whilst the overall accuracy was $70.64 \%$ with a kappa value of 0.6467 for the ANN classification method, and the overall accuracy of the SVM classification method was $77.01 \%$ with a kappa value of 0.7267 . Among the three different classification methods, the highest accuracy was obtained from MLC results obtained from Sentinel 2B data. According to typical kappa coefficient values (Tab. 1), the SVM and ANN accuracy are classified as a high accuracy level, while MLC accuracy is classified as a very high accuracy level.

Classification results illustrated that water classes (shallow and deep) could be successfully identified using the three methods (MLC, ANN, and SVM). The user and producer's accuracy values were very low for the urban class using MLC, however, it was zero for the ANN and the SVM. This is probably due to that this class covers a very small area, or due to the similarity of the spectral characteristics of the urban area and the barren soil.

The best fit was recorded when using the MLC classification method, where the accuracy percentages average $87.8 \%$ for the user and $84.7 \%$ for the producer; while the user and produce an accuracy percentages average for ANN classification method was $69.3 \%, 69.7 \%$, and for SVM classification method was $71.2 \%, 76.2 \%$ respectively. 


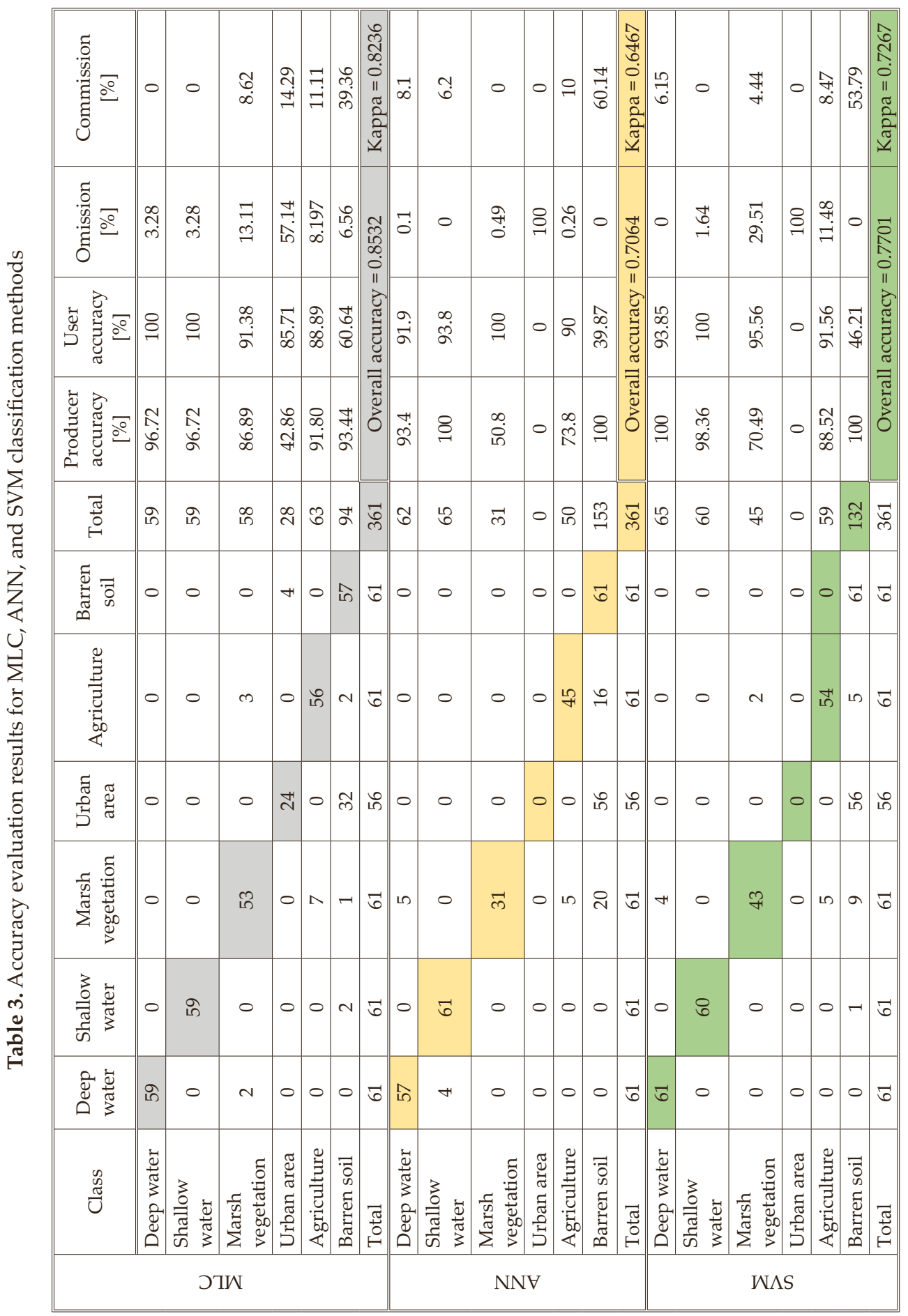




\section{Conclusions}

In this study, three classification methods were used to classify the land cover for the complex ecosystem of the Al-Hawizeh marsh on the Iraq-Iran border, aimed at comparing the accuracy using Sentinel 2B images with a spatial resolution of $10 \mathrm{~m}$. The classification process was carried out using MLC, ANN, and SVM to classify six land cover classes: deep water marsh, shallow water marsh, marsh vegetation, urban area, agriculture area, and barren soil. The overall accuracy and the kappa coefficient were used to compare these three classification methods. According to the confusion matrix, the overall accuracy of the MLC classification was better than SVM, and ANN classification, while ANN classification was the least accurate. This was also the case for the overall kappa statistics. Overall accuracy values for MLC, ANN, and SVM methods were $85.32 \%, 70.64 \%$, and $77.01 \%$ respectively. The best fit was obtained by using a MLC classification, where the average accuracy percentages were $87.8 \%$ for the user and $84.7 \%$ for the producer; while the user and produce an accuracy percentages average for ANN classification method was $69.3 \%, 69.7 \%$, and for the SVM classification method was 71.2\%, 76.2\% respectively. Additionally, the SVM and the ANN accuracy are classified as a high accuracy level, while the MLC accuracy is classified as a very high accuracy level according to typical kappa coefficient values.

\section{References}

[1] Chatelard G., Abulhawa T.: The World Heritage Nomination of the Ahwar of Southern Iraq: Refuge of Biodiversity and Relict Landscape of the Mesopotamian Cities. Arab Regional Centre for World Heritage, Manama, Kingdom of Bahrain 2015.

[2] Romano L.: The Mesopotamian Marshlands (Al-Ahwār) in the Past and Today. [in:] Collins P. (ed.), Basra: Its History, Culture and Heritage: Proceedings of the Conference Celebrating the Opening of the Basrah Museum, September 28-29, 2016, British Institute for the Study of Iraq, 2019, pp. 7-12.

[3] Albarakat R., Lakshmi V., Tucker C.J.: Using Satellite Remote Sensing to Study the Impact of Climate and Anthropogenic Changes in the Mesopotamian Marshlands, Iraq. Remote Sensing, vol. 10, 2018, 1524. https://doi.org/10.3390/ rs10101524.

[4] UNESCO: The Ahwar of Southern Iraq: Refuge of Biodiversity and the Relict Landscape of the Mesopotamian Cities. 1481, 2016.

[5] Partow H., Jaquet J.M., Allenbach K., Schwarzer S., Nordbeck O.: Iraqi Marshlands Observation System. United Nations Environment Programme (UNEP). UNEP Technical Report, Nairobi, Kenya 2005. 
[6] Richardson C.J., Reiss P., Hussain N.A., Alwash A.J., Pool D.J.: The restoration potential of the Mesopotamian marshes of Iraq. Science, vol. 307, issue 5713, 2005, pp. 1307-1311. https://doi.org/10.1126/science.1105750.

[7] Van Dessel W., Van Rompaey A., Poelmans L., Szilassi P.: Predicting land cover changes and their impact on the sediment influx in the Lake Balaton catchment. Landscape Ecology, vol. 23, 2008, pp. 645-656. https://doi.org/10.1007/ s10980-008-9227-6

[8] Ziboon A.R.T., Alwan I.A., Khalaf A.G.: Utilization of Remote Sensing Data and GIS Applications for Determination of the Land Cover Change in Karbala Governorate. Engineering and Technology Journal, vol. 31, 2013, pp. 2773-2787.

[9] Głowienka E., Michałowska K.: Analyzing the Impact of Simulated Multispectral Images on Water Classification Accuracy by Means of Spectral Characteristics. Geomatics and Environmental Engineering, vol. 14, no. 1, 2020, pp. 47-58. https://doi.org/10.7494/geom.2020.14.1.47.

[10] Hussein Z.E., Hasan R.H., Aziz N.A.: Detecting the Changes of AL-Hawizeh Marshland and Surrounding Areas Using GIS and Remote Sensing Techniques. Association of Arab Universities Journal of Engineering Sciences, vol. 25(1), 2018, pp. 53-63.

[11] Alwan I.A., Aziz N.A., Hamoodi M.N.: Potential Water Harvesting Sites Identification Using Spatial Multi-Criteria Evaluation in Maysan Province, Iraq. ISPRS International Journal of Geo-Information, vol. 9(4), 2020, 235. https://doi. org/10.3390/ijgi9040235.

[12] Hansen M., Dubayah R., DeFries R.: Classification trees: An alternative to traditional land cover classifiers. International Journal of Remote Sensing, vol. 17, 1996, pp. 1075-1081. https://doi.org/10.1080/01431169608949069.

[13] Pal M., Mather P.M.: An assessment of the effectiveness of decision tree methods for land cover classification. Remote Sensing of Environment, vol. 86, 2003, pp. 554-556. https://doi.org/10.1016/S0034-4257(03)00132-9.

[14] Khorram S.: Accuracy assessment of remote sensing-derived change detection. ASPRS Publications, American Society for Photogrammetry and Remote Sensing, 1999.

[15] Talukdar S., Singha P., Mahato S., Shahfahad Pal S., Liou Y.-A., Rahman A.: Land-Use Land-Cover Classification by Machine Learning Classifiers for Satellite Observations - A Review. Remote, vol. 12, 2020, 1135. https://doi.org/10.3390/ rs12071135.

[16] Nguyen H.T.T., Doan T.M., Tomppo E., McRoberts R.E.: Land Use/Land Cover Mapping Using Multitemporal Sentinel-2 Imagery and Four Classification Methods - A Case Study from Dak Nong, Vietnam. Remote Sensing, vol. 12, 2020, 1367. https://doi.org/10.3390/rs12091367.

[17] Al-Mudaffar F.N., Goodwin K.P., Mahdi B.A., Stevens M.L.: Effects of Mesopotamian Marsh (Iraq) desiccation on the cultural knowledge and livelihood of Marsh Arab women. Ecosystem Health and Sustainability, vol. 2(3), 2016, 1207. https://doi.org/10.1002/ehs2.1207. 
[18] Canadian-Iraq Marshlands Initiative (CIMI): Atlas of the Iraqi marshes. University of Victoria, Victoria, BC, 2010.

[19] Ministry of Water Resources (MOWR): Strategy for Water E Land Resources in Iraq/Final Report - Republic of Iraq. 2014.

[20] Alwan I.A., Karim H.H., Aziz N.A.: Agro-Climatic Zones (ACZ) Using Climate Satellite Data in Iraq Republic. IOP Conference Series: Materials Science and Engineering, vol. 518, issue 2, 2019, 022034. https://doi.org/10.1088/1757899X/518/2/022034.

[21] European Space Agency (ESA): MultiSpectral Instrument (MSI) Overview. Sentinel Online. https://earth.esa.int/web/sentinel/technical-guides/sentinel-2-msi/msi-instrument [access: 20.06.2020].

[22] ESA: Copernicus Open Access Hub. https://scihub.copernicus.eu/ [access: 24.06.2020].

[23] Ministry of Water Resources (MOWR): Study the Rehabilitation of AL Huwayza Marsh Ecological System. Survey Report, 2006 [unpublished].

[24] Thenkabail P.S.: Remote Sensing Handbook, Volume 1: Remotely Sensed Data Characterization, Classification, and Accuracies. Taylor \& Francis, 2016.

[25] Horning N.: Land cover classification methods. Remote Sensing \& Geographic Information Systems Facility. Remote Sensing Resources. Center for Biodiversity and Conservation at the American Museum of Natural History, 2004.

[26] Lefebvre A., Sannier C., Corpetti T.: Monitoring Urban Areas with Sentinel-2A Data: Application to the Update of the Copernicus High Resolution Layer Imperviousness Degree. Remote Sensing, vol. 8(7), 2016, 606. https://doi.org/10.3390/ rs8070606.

[27] Otukei J.R., Blaschke T.: Land cover change assessment using decision trees, support vector machines and maximum likelihood classification algorithms. International Journal of Applied Earth Observation and Geoinformation, vol. 12, 2010, pp. S27-S31. https://doi.org/10.1016/j.jag.2009.11.002.

[28] Tso B., Mather P.M.: Classification methods for remotely sensed data (No. LC0431). $2^{\text {nd }}$ ed. CRC Press, 2009.

[29] Vapnik V.N.: The Nature of Statistical Learning Theory. Springer, New York 1995.

[30] Mountrakis G., IM J., Ogole C.: Support vector machines in remote sensing: A review. ISPRS Journal of Photogrammetry and Remote Sensing, vol. 66, 2011, pp. 247-259. https://doi.org/10.1016/j.isprsjprs.2010.11.001.

[31] Zhao Q., Principe J.C.: Support vector machines for SAR automatic target recognition. IEEE Transactions on Aerospace and Electronic Systems, vol. 37, issue 2, pp. 643-654. https://doi.org/10.1109/7.937475.

[32] Canty M.J.: Image Analysis, Classification and Change Detection in Remote Sensing, with algorithms for ENVI/IDL. CRC Press, Boca Raton 2007.

[33] Cortes C., Vapnik V.: Support-vector networks. Machine Learning, vol. 20, 1995, pp. 273-297. https://doi.org/10.1007/BF00994018. 
[34] Saga-GIS Web Page: http://www.saga-gis.org/saga_tool_doc/2.2.0/imagery_ svm_0.html [access: 10.06.2020].

[35] Rumelhart D.E., Hinton G.E., Williams R.J.: Learning Internal Representations by Error Propagation. [in:] Rumelhart D., McClelland J.L.: Parallel distributed processing: explorations in the microstructure of cognition. Volume 1. Foundations, MIT Press, Cambridge, Massachusetts 1986, pp. 318-362.

[36] Richards J.A.: Remote Sensing Digital Image Analysis. Springer-Verlag, Berlin 1999.

[37] Richards J.A.: Remote Sensing Digital Image Analysis: An Introduction. Springer-Verlag, Berlin 2013.

[38] USGS: The Spatial Data Transfer Standard. United States Geological Survey, Draft, January 1990.

[39] Park M.H., Stenstrom M.K.: Classifying environmentally significant urban land uses with satellite imagery. Journal of Environmental Management, vol. 86(1), 2008, pp. 181-192. https://doi.org/10.1016/j.jenvman.2006.12.010.

[40] Cracknell M.J., Reading A.M.: Geological mapping using remote sensing data: A comparison of five machine learning algorithms, their response to variations in the spatial distribution of training data and the use of explicit spatial information. Computers \& Geosciences, vol. 63, 2014, pp. 22-33. https://doi.org/10.1016/ j.cageo.2013.10.008.

[41] Viera A.J., Garrett J.M.: Understanding interobserver agreement: The kappa statistic. Family Medicine, vol. 37(5), 2005, pp. 360-363.

[42] Bishop Y., Fienberg S., Holland P.: Discrete Multivariate Analysis: Theory and Practice. MIT Press, Cambridge, MA, 1975.

[43] Rosenfield G.H., Fitzpatrick-Lins K.: A coefficient of agreement as a measure of thematic classification accuracy. Photogrammetric Engineering and Remote Sensing, vol. 52(2), 1986, pp. 223-227.

[44] Kranjčić N., Medak D., Župan R., Rezo M.: Support Vector Machine Accuracy Assessment for Extracting Green Urban Areas in Towns. Remote Sensing, vol. 11(6), 2019, 655. https://doi.org/10.3390/rs11060655.

[45] Foody G.M.: Status of land cover classification accuracy assessment. Remote Sensing of Environment, vol. 80, 2002, pp. 185-201. https://doi.org/10.1016/ S0034-4257(01)00295-4.

[46] Congalton R.G., Green K.: Assessing the Accuracy of Remotely Sensed Data: Principles and Practices. $2^{\text {nd }}$ ed. CRC Press, 2008. 